\title{
Ciclesonide in persistent asthma: the evidence of its therapeutic value
}

\author{
Charlotte A. Kenreigh, Linda Timm Wagner, Paul Chrisp \\ MLC Solutions Ltd, Galena, Ohio, USA, and Core Medical Publishing, Knutsford, UK
}

\begin{abstract}
Introduction: Asthma, a respiratory disease associated with airway inflammation and hyperresponsiveness, is one of the most prevalent chronic diseases worldwide affecting both children and adults. Inhaled corticosteroids are considered to be the cornerstone of asthma management. Ciclesonide, an airway-activated inhaled corticosteroid, has been developed for the management of persistent asthma. Its once-daily administration and airway activation may be advantageous in the treatment of asthma.

Aims: The purpose of this article is to review the place in therapy of ciclesonide in the management of patients with persistent asthma based on the available clinical evidence.

Evidence review: The available evidence indicates that ciclesonide has an effect on pulmonary function (forced expiratory volume in $1 \mathrm{~s}$, forced vital capacity, and peak expiratory flow), as well as producing improvements in patient-reported symptoms that are equivalent to those achieved with other inhaled corticosteroids. A few studies have focused on health-related quality of life and have demonstrated a positive effect with ciclesonide treatment. Its pharmacokinetic profile may offer advantages in terms of adverse effects, both local and systemic, although most of the data come from 12-week studies.

Place in therapy: The current evidence shows that ciclesonide offers another alternative among inhaled corticosteroids, with the potential for fewer adverse effects. The unique pharmacokinetic profile of ciclesonide allows once-daily administration and the airway activation of the drug appears to confer clinical benefit in the treatment of asthma. Its lack of systemic adverse effects make it a viable option for pediatric use.
\end{abstract}

Key words: antiinflammatory, asthma, ciclesonide, evidence, inhaled corticosteroids, outcomes

\section{Core evidence place in therapy summary for ciclesonide in persistent asthma}

\begin{tabular}{|c|c|c|}
\hline Outcome measure & Evidence & Implications \\
\hline Improvement in asthma symptoms & Clear & Effects are similar to other inhaled corticosteroids \\
\hline Reduction in rescue medication & Clear & Effects are similar to other inhaled corticosteroids \\
\hline Improvement in quality of life & Substantial & Beneficial effects on patient-perceived quality of life \\
\hline \multicolumn{3}{|l|}{ Disease-oriented evidence } \\
\hline Preservation of hypothalamic-pituitary-adrenal axis & Substantial & $\begin{array}{l}\text { Lack of effect on hypothalamic-pituitary-adrenal axis for up to } 1 \text { year; suitable for use } \\
\text { in pediatric patients }\end{array}$ \\
\hline Lower incidence of local adverse effects & Clear & $\begin{array}{l}\text { Fewer local adverse effects (e.g. oropharyngeal effects) compared with other inhaled } \\
\text { corticosteroids }\end{array}$ \\
\hline $\begin{array}{l}\text { Cost effectiveness as an inhaled corticosteroid in } \\
\text { persistent asthma in adults and children }\end{array}$ & No evidence & Evidence required \\
\hline
\end{tabular}




\section{Scope, aims, and objectives}

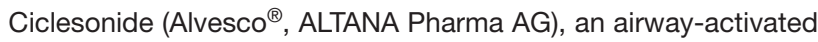
inhaled corticosteroid, has been developed for the management of persistent asthma. Its once-daily administration and airway activation may be advantageous in the treatment of asthma. Pharmacologically, the activation of ciclesonide to its active metabolite, desisobutyryl-ciclesonide (des-CIC), by airway esterases is novel. This local activation of drug provides concentrated activity of ciclesonide at the target organ, the lungs, and may decrease the potential for local and systemic adverse effects. Data from phase III clinical trials evaluating ciclesonide in the management of adult and pediatric patients with persistent asthma are available.

The purpose of this article is to review the place in therapy of ciclesonide in the management of patients with persistent asthma based on the available clinical evidence.

\section{Methods}

The English language medical literature was reviewed for appropriate articles relating to ciclesonide for the treatment of asthma. The following databases were searched during August 2005 using the search terms "ciclesonide," "El 876," "By 90107," and "Alvesco":

- PubMed, http://www.ncbi.nlm.nih.gov

- EMBASE, http://www.datastarweb.com

- BIOSIS, http://www.datastarweb.com

- York University Centre for Reviews and Dissemination (CRD) databases, http://www.york.ac.uk/inst/crd/crddatabases.htm

- National Guideline Clearinghouse, http://www.guideline.gov

- Clinical trial registries, http://www.clinicaltrials.gov, http://www.clinicalstudyresults.org

- National Coordinating Centre for Health Technology Assessment (NCCHTA), http://www.ncchta.org

- Cochrane Database of Systematic Reviews (CDSR), http://www.cochrane.org/index0.htm

- National Institute for Health and Clinical Evidence (NICE), http://www.nice.org.uk

- Clinical Evidence (BMJ), http://www.clinicalevidence.com

No date limitations were placed on the search and only studies in patients with asthma were included. Abstracts from the American Thoracic Society (ATS) (http://www.thoracic.org) and the European Respiratory Society (ERS) meetings (http://www.ersnet.org/ers) for 2002-2005 were also reviewed using the same search terms to identify studies that have not yet been published in full.

Numerous guidelines related to asthma management were identified, but only two recent guidelines applicable on a global level were considered relevant for this review. No studies were identified from a review of clinical trials databases. A single Health Technology Assessment of ciclesonide was identified from the York University Centre.

The levels of evidence identified from the literature searches are summarized in Table 1. Twenty full papers were identified in the initial search. Records were manually reviewed and 12 papers were excluded: pharmacokinetic $(n=5)$, in vitro $(n=1)$, animal studies $(n=2)$, study other than a large, controlled clinical trial $(n=3)$, or citations that mentioned ciclesonide but did not investigate its clinical use $(n=1)$. Sixty-one abstracts were also reviewed manually. Exclusions included: published in full $(n=4)$, pharmacokinetic $(n=5)$, animal studies $(n=6)$, in vitro $(n=10)$, study other than a large, controlled clinical trial $(n=11)$, and presentation of study results at more than one professional meeting $(n=6)$.

The search was updated on February 7 and on June 30, 2006 and 22 new records were identified from the previous search. Eleven records were excluded as they were nonsystematic reviews $(n=6)$, editorials $(n=1)$, in vitro $(n=2)$, small pharmacokinetic study $(n=1)$, or an indication other than asthma $(n=1)$. A systematic review (Dyer et al. 2006) was not included in the evidence base, as it was limited to small phase II studies comparing ciclesonide with other inhaled corticosteroids, rather than more recent larger phase III randomized controlled trials (RCTs).

\section{Table 1 | Evidence base included in the review}

\begin{tabular}{|c|c|c|}
\hline \multirow[t]{2}{*}{ Category } & \multicolumn{2}{|c|}{ Number of records } \\
\hline & Full papers & Abstracts \\
\hline Initial search & 20 & 61 \\
\hline records excluded & 12 & 42 \\
\hline records included & 8 & 19 \\
\hline Additional studies identified ${ }^{a}$ & 3 & 3 \\
\hline Search update, new records & 22 & 22 \\
\hline records excluded & 12 & 18 \\
\hline records included & 10 & 4 \\
\hline Level 1 clinical evidence & 2 & 0 \\
\hline Level 2 clinical evidence & 18 & $27^{b}$ \\
\hline Level $\geq 3$ clinical evidence & 1 & 0 \\
\hline trials other than RCT & 1 & \\
\hline \multicolumn{3}{|l|}{ case reports } \\
\hline Economic evidence & 0 & 0 \\
\hline Total records included & 21 & 27 \\
\hline \multicolumn{3}{|c|}{$\begin{array}{l}\text { aAdditional studies identified = any relevant study that was picked up from a source o } \\
\text { than the main searches, e.g. a reference list. } \\
\text { bIncludes several subanalyses from six RCTs. } \\
\text { For definitions of levels of evidence see Editorial Information on inside back cover. } \\
\text { RCT, randomized controlled trial. }\end{array}$} \\
\hline
\end{tabular}


In addition, a further level 3 pharmacokinetic study was identified and included (Nave et al. 2006), along with 22 abstracts of meeting presentations, of which 4 were included following removal of duplicates.

\section{Disease overview}

Asthma, a chronic respiratory disease of both children and adults, is one of the most prevalent chronic diseases in the world affecting approximately 300 million people (Bousquet et al. 2005; Masoli et al. 2005). An estimated 250000 deaths caused by asthma occur annually; one in every 250 deaths worldwide is thought to be secondary to asthma (Bousquet et al. 2005; Masoli et al. 2005).

The impact of asthma is far-reaching in both the adult and pediatric population and includes an effect on activities of daily living that extends to participation in school, work, and family life. Globally, about 15 million disability-adjusted life years (DALYs) are lost annually due to asthma, a number similar to that associated with diabetes, cirrhosis, or schizophrenia (Masoli et al. 2005). Direct medical costs related to medications and hospital admissions, and indirect medical costs related to loss of work and premature mortality are significant. Direct medical costs of asthma treatment account for up to $3 \%$ of total medical expenditures for many countries (Bousquet et al. 2005).

Although the exact etiology of asthma remains poorly understood it is thought to have both genetic and environmental causes and is considered a chronic inflammatory disease. Asthma is characterized by bronchial hyperreactivity caused by chronic inflammation of the airways. Bronchial hyperreactivity is associated with reversible airflow obstruction and episodes of wheezing, breathlessness, chest tightness, and coughing (especially in the early morning or at night). There is no cure for asthma and the goal of treatment is to achieve and maintain control of symptoms, prevent exacerbations, reduce/eliminate side effects from medications, and allow patients to have an optimal quality of life. The potential for development of adverse effects associated with asthma treatment has been noted to impact patient adherence to therapy (Goeman 2002).

\section{Current therapy options}

Over the past two decades the treatment of asthma has received increased attention and guidelines for the management of asthma have been published [Global Initiative for Asthma (GINA) strategy, World Health Organization (WHO)/National Heart, Lung, and Blood Institute (NHLBI); Anon. 2005b). A global strategy for asthma management and prevention-the result of a collaborative effort of GINA, WHO, and the NHLBI-was first issued in 1995. Updates to this guideline have been released with the most recent being in 2004. Asthma management protocols and guidelines focus on the inflammatory component of the disease and recommend a stepped-care approach to disease management (Table 2).

Many pharmacologic entities are available for the chronic management of persistent asthma, but inhaled corticosteroids are the cornerstone of therapy. Corticosteroids can be administered either orally or via inhalation, although the adverse effect profile significantly favors the latter. Inhaled corticosteroids are considered the most effective therapy for persistent asthma and are the preferred treatment for all patients with persistent disease symptoms (Anon. 2005b).

All of the available inhaled corticosteroids produce their effects by interacting with intracellular glucocorticoid receptors, which are present throughout the body. In the treatment of asthma, the effect of these agents on pulmonary glucocorticoid receptors produce the desired effects but interaction with glucocorticoid receptors outside the lungs can lead to unwanted adverse effects such as suppression of the hypothalamic-pituitary-adrenal axis (HPA), reduction of bone density, and growth suppression. Beneficial pharmacologic effects of these agents include decreasing inflammatory cells in the airway and increasing the release of antiinflammatory cytokines (Hübner et al. 2005). The decrease in inflammatory mediators results in a reduction of airway inflammation and hyperreactivity, improved pulmonary function, symptom control, and reduction of exacerbations (Kelly 2003).

The principal goal of inhaled corticosteroid therapy is to have a high level of antiinflammatory effect with minimal adverse effects (Kelly 2003). Although differences in pharmacokinetic parameters and potency exist, the currently available agents (Table 3) are considered equally efficacious when administered at equipotent doses (O'Connell 2005). The ideal inhaled corticosteroid for patients with asthma has a high degree of lung deposition with a low level of systemic bioavailability providing therapeutic benefit (high glucocorticoid receptor affinity) without significant adverse effects. Systemic exposure can be minimized by high protein binding and a rapid clearance rate (Berger 2005). Use of a prodrug that is not pharmacologically active until it undergoes a metabolic transformation has been shown to decrease oropharyngeal effects and might result in improved pulmonary targeting (Hübner et al. 2005).

Smaller particle size, physical properties of the compounds, delivery device used, and inhaler technique all have an impact on the rate of lung deposition (Hübner et al. 2005). Higher rates of lung deposition translate to an increased amount of drug available at the intended site of action (lungs) and a lower amount available for oral absorption and systemic availability, and hence fewer adverse effects. In addition, lipid conjugation of the compound can provide a reservoir in the lungs allowing for a slow release of active compound (Berger 2005).

Of particular concern for long-term treatment of persistent asthma is an agent's propensity to cause systemic side effects. Systemic exposure to an inhaled corticosteroid is tied to its potential for adverse effects. There is little concern about systemic effects with the use of low-dose inhaled corticosteroids (doses of $\leq 500 \mathrm{mcg}$ budesonide or equivalent) (Anon. 2005b). However, at high doses concern remains that these medications may cause HPA axis suppression, decreased bone mineralization, cataracts, glaucoma, and a reduction in the rate of bone growth in children. It is important to note that while HPA axis suppression 


\section{Table 2 | Pharmacologic management of asthma: stepped approach (adapted from Anon. 2005b)}

\section{Category of asthma}

Adults and children $>5$ years

Intermittent

Mild persistent

Moderate persistent

Severe persistent

Mild persistent

Moderate persistent

Severe persistent

\section{Characteristics}

- Symptoms <once/week

- Brief exacerbations

- Nocturnal symptoms $\leq 2$ nights/month

- $\mathrm{FEV}_{1}$ or $\mathrm{PEF} \geq 80 \%$ predicted

- PEF or $\mathrm{FEV}_{1}$ variability $<20 \%$

- Symptoms >once/week, but <once/day

- Exacerbations may affect activity and sleep

- Nocturnal symptoms >2 nights/month

- $\mathrm{FEV}_{1}$ or $\mathrm{PEF} \geq 80 \%$ predicted

- $\mathrm{PEF}$ or $\mathrm{FEV}_{1}$ variability $20-30 \%$

- Daily symptoms

- Exacerbations may affect activity and sleep

- Nocturnal symptoms >once/week

- Daily use of short-acting inhaled beta ${ }_{2}$ agonist

- $\mathrm{FEV}_{1}$ or PEF $60-80 \%$ predicted

- $\mathrm{PEF}$ or $\mathrm{FEV}_{1}$ variability $>30 \%$

- Continuous symptoms

- Frequent exacerbations

- Frequent nocturnal symptoms

- Limitation of physical activities

- $\mathrm{FEV}_{1}$ or PEF $60 \%$ predicted

- $\mathrm{PEF}$ or $\mathrm{FEV}_{1}$ variability $>30 \%$

- Symptoms <once/week

- Brief exacerbations

- Nocturnal symptoms <2 nights/month

- $\mathrm{FEV}_{1}$ or $\mathrm{PEF} \geq 80 \%$ predicted

- PEF or FEV 1 variability $<20 \%$

- Symptoms >once/week, but <once/day

- Exacerbations may affect activity

- Nocturnal symptoms >2 nights/month

- $\mathrm{FEV}_{1}$ or $\mathrm{PEF} \geq 80 \%$ predicted

- PEF or FEV 1 variability $20-30 \%$

- Daily symptoms

- Exacerbations affect activity

- Nocturnal symptoms >once/week

- $\mathrm{FEV}_{1}$ or PEF $60-80 \%$ predicted

- $\mathrm{PEF}$ or $\mathrm{FEV}_{1}$ variability $>30 \%$
Daily medication

- None

- Low-dose inhaled corticosteroid

- Alternative: cromolyn, leukotriene modifier, nedocromil, or sustained-release theophylline

- Low to medium-dose inhaled corticosteroid and long-acting inhaled beta ${ }_{2}$ agonist

- Alternative:

- Increase inhaled corticosteroid within medium dose range or

- Low to medium-dose inhaled corticosteroid and either leukotriene modifier or theophylline

- High-dose inhaled corticosteroid and long-acting inhaled beta $_{2}$ agonist

- If needed: oral corticosteroid, sustained-release theophylline, leukotriene modifier, antiimmunoglobulin $\mathrm{E}$ antibody (adults and children $\geq 2$ years)

- None

- Low-dose inhaled corticosteroid

- Alternative: cromolyn, leukotriene modifier, nedocromil, or sustained-release theophylline

- Low-dose inhaled corticosteroid and long-acting inhaled beta $_{2}$ agonist (if needed medium dose can be used)

or

- Medium-dose inhaled corticosteroid

- Alternative: low-dose inhaled corticosteroid (if needed medium dose can be used) and leukotriene modifier or theophylline

- High-dose inhaled corticosteroid and long-acting inhaled beta $_{2}$ agonist

- If needed: oral corticosteroid
- Frequent nocturnal symptoms

- Limitation of physical activity

- $\mathrm{FEV}_{1}$ or PEF $\leq 60 \%$ predicted

- $\mathrm{PEF}$ or $\mathrm{FEV}_{1}$ variability $>30 \%$

aA short-acting inhaled beta ${ }_{2}$ agonist should be used as needed to relieve acute symptoms; use should be limited to no more than 3-4 times/day.

${ }^{\text {b} C h i l d r e n ~ w i t h ~ i n t e r m i t t e n t ~ a s t h m a ~ b u t ~ s e v e r e ~ e x a c e r b a t i o n s ~ s h o u l d ~ b e ~ m a n a g e d ~ a s ~ h a v i n g ~ m o d e r a t e ~ p e r s i s t e n t ~ a s t h m a . ~}$

$\mathrm{FEV}_{1}$, forced expiratory volume in $1 \mathrm{~s}$; PEF, peak expiratory flow. 
Table 3 | Pharmacokinetic profiles of currently available inhaled corticosteroids (Reynolds \& Scott 2004; Anon. 2005a; Hübner et al. 2005; Wickersham \& Novak 2005)

\begin{tabular}{|c|c|c|c|c|c|c|}
\hline Drug & $\begin{array}{l}\text { Lung deposition } \\
\text { (MDI-HFA) (\%) }\end{array}$ & $\begin{array}{l}\text { Oral } \\
\text { bioavailabilitya (\%) }\end{array}$ & Protein binding (\%) & Metabolism & Excretion & $\begin{array}{l}\text { Suggested dosing } \\
\text { frequency }\end{array}$ \\
\hline $\begin{array}{l}\text { Beclomethasone } \\
\text { propionate }\end{array}$ & $51^{\mathrm{b}}$ & 26 & 87 & Hepatic & Feces, urine $(<10 \%)$ & Twice daily \\
\hline Budesonide & 28 & $11-32$ & 88 & Hepatic & Urine $(60 \%)$, feces & Once or twice daily ${ }^{a}$ \\
\hline Ciclesonide & 52 & $<1$ & 99 & Hepatic & Feces $(77.9 \%)$ & Once daily \\
\hline Flunisolide & 39 & 7 & 80 & Hepatic & Renal (50\%), feces (40\%) & Twice daily \\
\hline $\begin{array}{l}\text { Fluticasone } \\
\text { propionate }\end{array}$ & 16 & $<1$ & 90 & Hepatic & Feces (urine $<0.02 \%$ ) & Twice daily \\
\hline Mometasone furoate & - & 11 & $98-99$ & Hepatic & Feces $(74 \%)$, urine $(8 \%)$ & Once or twice daily \\
\hline $\begin{array}{l}\text { Triamcinolone } \\
\text { acetonide }\end{array}$ & $22^{b}$ & 21.5 & 71 & $\begin{array}{l}\text { Mostly hepatic, } \\
\text { some renal }\end{array}$ & Urine $(40 \%)$, feces $(60 \%)$ & Twice daily \\
\hline $\begin{array}{l}\text { aDepends on the delivery } \\
\text { bDelivery device not spec } \\
\text { MDI-HFA metered-dose }\end{array}$ & ice used. & 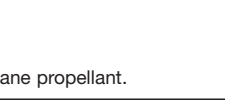 & & & & \\
\hline
\end{tabular}

and decreased osteoblast activity have been reported with highdose inhaled corticosteroid therapy, the clinical significance of these effects is controversial. Additionally, patients receiving high doses of inhaled corticosteroids may be exposed to intermittent courses of systemic glucocorticoids that complicate the assessment of the impact of high-dose inhaled corticosteroid treatment alone (Anon. 2005b). Of the available inhaled corticosteroids, comparative studies have shown that budesonide, mometasone, and fluticasone have a lower potential to cause systemic effects as compared with beclomethasone dipropionate and triamcinolone (Crim et al. 2001; Anon. 2005b).

Ideally, once a patient's symptoms are controlled, the dose of inhaled corticosteroid should be reduced to the minimum effective dose to promote safe and cost-effective asthma control (British Thoracic Society 2005). Unfortunately, this approach is not always undertaken and patients are not infrequently exposed to unnecessarily high doses and an increased risk of adverse effects (O'Connell 2005).

Beyond the specific drug selected, the device used to deliver the therapeutic entity can have a profound effect on treatment outcome. In an attempt to maximize drug delivery to the lungs, a variety of inhaler devices have been developed. The device also impacts the efficacy of therapy and has associated advantages and disadvantages (Table 4). The delivery device as well as the specific drug evaluated and the dose selected must all be considered when evidence of inhaled corticosteroid efficacy and adverse effects are taken into account. Environmental concerns have mandated alternatives to the use of chlorofluorocarbon (CFC) propellants in metered-dose inhalers. The change to hydrofluoroalkane propellants has resulted in some products that have different characteristics from previous formulations (Dolovich et al. 2005). Therefore, interpretation of reported efficacy and adverse effect data also requires an understanding of the propellant used.
Even at low daily doses, local adverse effects (dysphonia, oral candidiasis, and pharyngitis) to inhaled corticosteroids are reported at widely varying rates (5-58\%) (Roland et al. 2004). The reported prevalence of these local effects is influenced by the type of study, length of observation, delivery device used, and method for recording (questionnaire or clinical examination). Local adverse effects may complicate treatment and lead to a disruption of therapy and worsening of disease.

Despite advances in delivery device and drug development, there is still a need for inhaled corticosteroid therapies that are highly specific to the site of action, the lungs, with minimal systemic absorption. Ciclesonide was developed in response to this need.

\section{Clinical evidence with ciclesonide in asthma}

Level 2 evidence from fully published studies investigating the efficacy and safety of ciclesonide is available, including placebocontrolled studies (Chapman et al. 2005; Langdon et al. 2005; Pearlman et al. 2005; Bateman et al. 2006b; Gelfand et al. 2006) and trials with active comparator (Buhl et al. 2005a; Niphadkar et al. 2005; Boulet et al. 2006a; Hansel et al. 2006). Further evidence is also currently available in abstract form only, hindering full critical appraisal. Outcomes studied include disease-oriented measurable endpoints of respiratory function, inflammatory markers, and HPA suppression, as well as patient-oriented outcomes such as asthma symptoms, health-related quality of life (HRQOL), and use of rescue medication. Comparator drug propellant is not consistently reported which makes an assessment of delivery device difficult.

Ciclesonide is a prodrug whereas the other inhaled corticosteroids are delivered to the site of action in their active form. Ciclesonide is converted to its active and highly potent metabolite, des-CIC, by esterases in the airways, thus providing active drug at the intended site of action. Ciclesonide is also 
Table 4 | Advantages and disadvantages of portable delivery devices for inhaled corticosteroids (Dolovich et al. 2005)

\begin{tabular}{|lll|}
\hline Device & Advantages & Disadvantages \\
\hline Pressurized metered-dose inhaler & $\begin{array}{l}\text { No contamination } \\
\text { Dose-dose reproducibility } \\
\text { Some can be used with breath-actuated } \\
\text { mouthpiece }\end{array}$ & $\begin{array}{l}\text { Requires coordination and good technique } \\
\text { High pharyngeal deposition } \\
\text { Difficult to determine remaining dosage }\end{array}$ \\
Holding chamber, spacers & $\begin{array}{l}\text { Decreased need for patient coordination } \\
\text { Decreased pharyngeal deposition }\end{array}$ & $\begin{array}{l}\text { Added expense } \\
\text { Less portable than metered-dose inhaler alone } \\
\text { Dose delivered might be reduced }\end{array}$ \\
Dry-powder inhalers & Less patient coordination required: breath actuated \\
& No propellant required & $\begin{array}{l}\text { Can deliver high pharyngeal deposition } \\
\text { Mose counters in most newer dosage forms }\end{array}$ \\
& actuation high inspiratory flow required for
\end{tabular}

formulated in solution which in comparison with suspensions is likely to improve lung deposition characteristics (Berger 2005). In addition, other properties of ciclesonide and des-CIC, including low oral bioavailability $(<1 \%)$, rapid systemic clearance and a high degree of plasma protein binding (99\%) are designed to reduce the potential for systemic side effects.

Therefore, the pharmacologic and pharmacokinetic characteristics of ciclesonide are intended to provide advancements in the treatment of asthma with a potentially improved safety profile.

\section{Systemic absorption}

In human lung tissue, a reversible lipid conjugation of des-CIC has been demonstrated. This may account for the prolonged antiinflammatory activity of inhaled ciclesonide in the lungs as this conjugated des-CIC may act as a reservoir (Berger 2005).

The small particle size of ciclesonide improves its pulmonary deposition; studies have shown that up to $52 \%$ of an inhaled dose of ciclesonide is deposited in the small airways and alveoli following administration, and that the amount of deposition is not influenced by the use of a spacer device (Drollmann et al. 2006; Newman et al. 2006). The pharmacokinetics of ciclesonide and des-CIC are similar in healthy subjects and in patients with asthma, confirming that airway activation of the drug is unimpaired by the disease (Nave et al. 2006).

Compared with fluticasone and budesonide, smaller amounts of ciclesonide are available for systemic absorption through the gastrointestinal tract as lower amounts are deposited in the mouth and oropharynx. In a study of adults with bronchial asthma, the oropharyngeal deposition of ciclesonide was about $50 \%$ of that reported with fluticasone propionate, with $90 \%$ less des-CIC present in the oropharyngeal cavity compared with fluticasone following inhalation (Richter et al. 2005). Following administration of ciclesonide and budesonide to healthy volunteers, the maximal concentrations of ciclesonide and des-CIC recovered from oropharyngeal wash were $30 \%$ and $0.67 \%$ of budesonide, respectively (Nave et al. 2005a). Ciclesonide and budesonide concentrations in the wash decreased rapidly within 15 min of administration. The concentrations of des-CIC in the oropharynx 60 min after inhalation were only $4 \%$ of the budesonide concentration (Nave et al. 2005a), and $8 \%$ of the fluticasone concentration (Richter et al. 2005).

Ciclesonide undergoes first-pass hepatic inactivation (>99\%) following oral administration, rendering systemic bioavailability from the oral route essentially negligible (Nave et al. 2004). Furthermore, there is a low potential for adverse systemic side effects with inhaled ciclesonide as it is highly protein bound (>99\%) and a low fraction of unbound active metabolite is available in the systemic circulation (Rohatagi et al. 2005). The unbound fraction is also rapidly cleared further limiting systemic availability (Berger 2005).

\section{Pulmonary function}

Laboratory measures of forced expiratory volume in $1 \mathrm{~s}\left(\mathrm{FEV}_{1}\right)$, forced vital capacity (FVC), and peak expiratory flow (PEF) provide a direct, objective measure of treatment effect on airflow limitation in asthma. Use of a spirometer to assess $\mathrm{FEV}_{1}$ and FVC is helpful for diagnosing and monitoring the progress of asthma and response to therapy. Measurement of PEF with a peak expiratory flow meter can provide additional asthma monitoring information. However, PEF measures are not interchangeable with $\mathrm{FEV}_{1}$ and FVC, and do not always correlate with asthma severity; the relationship between $\mathrm{FEV}_{1}$ and PEF and asthma severity, airway inflammation, and HRQOL is complex and not well established.

Initial phase II studies documented a decrease in airway hyperresponsiveness after adenosine monophosphate (AMP) challenges with ciclesonide therapy; efficacy was similar to that of both fluticasone and budesonide (Taylor et al. 1999; Kanniess et al. 2001; Lee et al. 2004; Derom et al. 2005).

In placebo-controlled trials, ciclesonide demonstrated improvements in pulmonary function over a range of doses in patients with asthma with varying degrees of severity from mild to severe (Table 5). Single daily ciclesonide doses of at least $80 \mathrm{mcg}$ daily were associated with significant improvements from baseline in pulmonary function compared with placebo (Langdon et al. 2005). Studies comparing single daily ciclesonide doses of 800 and $1600 \mathrm{mcg}$ have not demonstrated superiority of the higher dose regimen (Chapman et al. 2002; O'Connor et al. 
Table 5 | Effect of ciclesonide on lung function in patients with moderate to severe asthma (level 2 evidence; all trials randomized, double-blind, parallel-group, placebo-controlled, 12 weeks' duration)

\begin{tabular}{|c|c|c|c|c|c|c|c|}
\hline \multirow[t]{2}{*}{ Treatment (mcg) } & \multirow[t]{2}{*}{$\mathbf{n}$} & \multirow{2}{*}{$\begin{array}{l}\text { Baseline } \text { FEV }_{1} \\
\text { (\% of predicted) }\end{array}$} & \multicolumn{4}{|c|}{ Outcome } & \multirow[t]{2}{*}{ Reference } \\
\hline & & & $\mathrm{FEV}_{1}(\mathrm{~mL})$ & $\begin{array}{l}\text { FEV }_{1}(\%) \text { change } \\
\text { from baseline }\end{array}$ & FVC $(m L)$ & Morning PEF (L/min) & \\
\hline $\mathrm{CIC} 160 \mathrm{qd}$ & 107 & \multirow[t]{3}{*}{$60-90$} & \multirow{3}{*}{$\begin{array}{l}\text { Maintained with } \\
\text { both doses }{ }^{a} \\
-144\end{array}$} & \multirow[t]{3}{*}{ NR } & +59 & \multirow{2}{*}{$\begin{array}{l}\text { Stable for both doses } \\
(P<0.0001)\end{array}$} & \multirow{3}{*}{$\begin{array}{l}\text { Chapman et al. } \\
2005\end{array}$} \\
\hline $\mathrm{CIC} 640 \mathrm{qd}$ & 112 & & & & +9 & & \\
\hline Placebo & 110 & & & & -161 & -29 & \\
\hline $\mathrm{CIC} 80 \mathrm{qd}$ & 120 & \multirow[t]{3}{*}{$60-95$} & $+130(P=0.0044)^{\mathrm{b}}$ & \multirow[t]{3}{*}{ NR } & $+190(P=0.0203)^{\mathrm{b}}$ & $+2^{\mathrm{c}}(P=0.0012)^{\mathrm{b}}$ & \multirow{3}{*}{$\begin{array}{l}\text { Langdon et al. } \\
2005\end{array}$} \\
\hline CIC 320 qd & 115 & & $+190(P=0.0001)^{\mathrm{b}}$ & & $+200(P=0.0197)^{\mathrm{b}}$ & $+3^{\mathrm{c}}(P=0.0006)^{\mathrm{b}}$ & \\
\hline Placebo & 125 & & -30 & & +40 & -18 & \\
\hline $\mathrm{CIC} 80 \mathrm{qd}$ & 257 & \multirow[t]{4}{*}{$60-85$} & $+280(P \leq 0.0007)^{\mathrm{b}}$ & \multirow[t]{4}{*}{ NR } & \multirow[t]{4}{*}{ NR } & $10.93^{\mathrm{c}}(P=0.0003)^{\mathrm{b}}$ & \multirow{4}{*}{$\begin{array}{l}\text { Pearlman et al. } \\
2005\end{array}$} \\
\hline CIC 160 qd & 250 & & $+290(P \leq 0.0007)^{\mathrm{b}}$ & & & $21.06^{\mathrm{c}}(P<0.0001)^{\mathrm{b}}$ & \\
\hline $\mathrm{CIC} 320$ qd & 255 & & $+310(P \leq 0.0007)^{\mathrm{b}}$ & & & $17.22^{\mathrm{c}}(P<0.0001)^{\mathrm{b}}$ & \\
\hline Placebo & 249 & & +170 & & & $-1.70^{c}$ & \\
\hline CIC 320 bid $^{d}$ & 47 & \multirow[t]{3}{*}{$40-80$} & \multirow{3}{*}{$\begin{array}{l}\text { Trend toward higher } \\
\text { values }^{\mathrm{e}} \\
\text { NR }\end{array}$} & NR & NR & $+4.32^{\mathrm{b}, \mathrm{c}}$ & \multirow{3}{*}{$\begin{array}{l}\text { Bateman et al. } \\
\text { 2006b }\end{array}$} \\
\hline CIC 640 bid $^{d}$ & 49 & & & NR & NR & $+15.97^{b, c}$ & \\
\hline Placebo $^{d}$ & 45 & & & NR & NR & $-0.7^{b, c}$ & \\
\hline \multicolumn{8}{|c|}{$\begin{array}{l}\text { All } P \text { values vs placebo. } \\
\text { a } P=0.007 \text { for } \mathrm{CIC} 160 \text { and } P=0.0108 \text { for } \mathrm{CIC} 640 . \\
\text { bReported as a mean value. } \\
\text { 'PEF change from baseline to week } 12 . \\
\text { dPatients also received oral prednisone } 5-30 \mathrm{mg} / \text { day and/or } 10-60 \mathrm{mg} \text { on alternate days. } \\
\text { e } P=0.0237 \mathrm{CIC} 320 \text { bid vs placebo, } P=0.0277 \mathrm{CIC} 640 \text { bid vs placebo. } \\
+, \text { increase over study period; }- \text {, decrease over study period; bid, twice daily; CIC, ciclesonide; FEV } 1 \text {, forced expiratory volume in } 1 \mathrm{~s} \text {; FVC, forced vital capacity; NR, not reported; NS, not } \\
\text { significant; } P E F \text {, peak expiratory flow; qd, once daily. }\end{array}$} \\
\hline
\end{tabular}

2002). More recent data, however, show that compared with ciclesonide $160 \mathrm{mcg}$ once daily, ciclesonide $320 \mathrm{mcg}$ twice daily resulted in significantly improved PEF $(P=0.0014)$ in 680 patients with severe asthma (Bateman et al. 2006a). A dose-response effect was also demonstrated in a 3-week study investigating ciclesonide $40,80,160$, and $320 \mathrm{mcg}$ on exercise-induced bronchoconstriction in 26 patients with mild asthma (Subbarao et al. 2006). Daily dosing given either in the morning or in the evening is associated with positive treatment response (Postma et al. 2001).

Ciclesonide $80 \mathrm{mcg}$ has also been shown to block allergeninduced lung function responses and measures of airway inflammation in patients with mild atopic asthma (Gauvreau et al. 2005). In this randomized three-way crossover study 21 patients were treated with ciclesonide 40 or $80 \mathrm{mcg}$ or placebo for 7 days and challenged with inhaled allergen. Compared with placebo, ciclesonide $80 \mathrm{mcg} /$ day attenuated the allergen-induced airway response $(P<0.025)$, the sustained fall in $\mathrm{FEV}_{1}$ measures 24 hours postchallenge $(P<0.025)$, and the allergen-induced accumulation of eosinophils into the airways $(P<0.025)$. Similarly, after 4 weeks of treatment with ciclesonide $160 \mathrm{mcg}$ once daily, inflammatory response as assessed by AMP bronchial challenge, exhaled nitric oxide, and sputum eosinophil count was significantly reduced in 17 patients with asthma (Wilson et al. 2006).

In larger studies comparing ciclesonide treatment with an active control, significant improvements in airflow (changes in $\mathrm{FEV}_{1}$ and FVC) were reported with ciclesonide and active control in all studies-with the exception of Boulet et al. (2006a) (Table 6). Neither treatment with budesonide nor ciclesonide resulted in improved $\mathrm{FEV}_{1}$ or FVC; however, the decrease in FVC was significantly less with ciclesonide than with budesonide $(P=0.01)$. The decline in $\mathrm{FEV}_{1}$ seen with both drugs was expected, since all patients routinely required "moderate" doses of inhaled corticosteroids to control their asthma, were poorly controlled, and had received budesonide $1280 \mathrm{mcg} / \mathrm{day}$ during a 2- to 4-week run-in phase, which was stopped prior to randomization to the study regimens. A subsequent abstract by the same authors reported that treatment with ciclesonide $320 \mathrm{mcg}$ once daily and fluticasone propionate $200 \mathrm{mcg}$ twice daily improved $\mathrm{FEV}_{1}$ to a comparable degree $(171 \mathrm{~mL}$ and $186 \mathrm{~mL}$, respectively; $P<0.0001$ vs baseline) (Boulet et al. 2006b).

PEF values were also significantly improved from baseline with ciclesonide and active treatment (Table 6). In one study comparing 
Table 6 | Effect on lung function of ciclesonide compared with active treatment in patients aged $>12$ years with moderate to severe asthma (level 2 evidence; all trials double-blind unless stated)

\begin{tabular}{|c|c|c|c|c|c|c|c|c|}
\hline \multirow{2}{*}{$\begin{array}{l}\text { Treatment (mcg) } \\
\text { [duration] }\end{array}$} & \multirow[t]{2}{*}{$\mathbf{n}$} & \multirow{2}{*}{$\begin{array}{l}\text { Baseline } \\
\text { FEV }_{1} \\
\text { (\% of } \\
\text { predicted) }\end{array}$} & \multicolumn{5}{|c|}{ Outcome } & \multirow[t]{2}{*}{ Reference } \\
\hline & & & $\mathrm{FEV}_{1}(\mathrm{~mL})$ & $\begin{array}{l}\mathrm{FEV}_{1}(\%) \text { change } \\
\text { from baseline }\end{array}$ & FVC $(m L)$ & $\begin{array}{l}\text { Morning PEF } \\
\text { (L/min) }\end{array}$ & $\begin{array}{l}\text { Evening PEF } \\
\text { (L/min) }\end{array}$ & \\
\hline $\begin{array}{l}\text { CIC } 320 \mathrm{qd} \\
\text { BUD } 400 \mathrm{qd} \\
{[12 \mathrm{w}]}\end{array}$ & $399^{a}$ & $50-90$ & $\begin{array}{l}+411^{\mathrm{c}} \\
+319^{\mathrm{c}} \\
\mathrm{CIC}>\mathrm{BUD} \\
(P=0.0374)\end{array}$ & NR & $\begin{array}{l}\text { Increase in both } \\
\text { groups (no values } \\
\text { given); CIC>BUD } \\
(P=0.0359)\end{array}$ & NR & NR & $\begin{array}{l}\text { Biberger } \\
\text { et al. } 2003\end{array}$ \\
\hline $\begin{array}{l}\text { CIC } 160 \text { qd } \\
\text { FP } 88 \text { bid } \\
{[12 w]}\end{array}$ & $\begin{array}{l}266 \\
263\end{array}$ & $80-100$ & $\begin{array}{l}+489^{c} \\
+499^{c}\end{array}$ & $\begin{array}{l}+20.45 \\
+20.4\end{array}$ & $\begin{array}{l}+530^{c} \\
+499^{c}\end{array}$ & $\begin{array}{l}+33^{\mathrm{c}} \\
+36^{\mathrm{c}}\end{array}$ & NR & $\begin{array}{l}\text { Buhl et al. } \\
2005 a\end{array}$ \\
\hline $\begin{array}{l}\text { CIC } 160 \text { qd A } \\
\text { CIC } 160 \text { qd P } \\
\text { BUD } 200 \text { bid } \\
{[12 \mathrm{w}]}\end{array}$ & $\begin{array}{l}139 \\
131 \\
133\end{array}$ & $\geq 70$ & $\begin{array}{l}-36^{d} \\
(P=0.383) \\
+22^{d} \\
(P=0.598) \\
0\end{array}$ & NR & $\begin{array}{l}+5^{\mathrm{d}}(P=0.905) \\
+2^{\mathrm{d}}(P=0.970) \\
0\end{array}$ & $\begin{array}{l}-4.4^{\mathrm{d}}(P=0.464) \\
+9.3^{\mathrm{d}}(P=0.131) \\
0\end{array}$ & $\begin{array}{l}-1.1^{d}(P=0.855) \\
+4.0^{d}(P=0.490) \\
0\end{array}$ & $\begin{array}{l}\text { Niphadkar } \\
\text { et al. } 2005\end{array}$ \\
\hline $\begin{array}{l}\text { CIC } 160 \text { bid } \\
\text { CIC } 320 \text { bid } \\
\text { FP } 440 \text { bid }^{b} \\
\text { Placebo } \\
{[12 \mathrm{w}]}\end{array}$ & $531^{a}$ & 54 & NR & $\begin{array}{l}+21.24^{c} \\
+24.46^{c} \\
+30.09^{c}\end{array}$ & NR & $\begin{array}{l}18.11^{c} \\
20.71^{c} \\
31.73^{c} \\
-9.69^{c}\end{array}$ & NR & $\begin{array}{l}\text { Weinstein } \\
\text { et al. } 2005\end{array}$ \\
\hline $\begin{array}{l}\text { CIC } 320 \text { qd } \\
\text { CIC } 320 \text { bid } \\
\text { BUD } 400 \text { bid } \\
{[8 \mathrm{w}]}\end{array}$ & $319^{a, e}$ & NR & NR & NR & NR & $\begin{array}{l}+16^{c} \\
+24^{c}(P=0.001 \text { vs BUD }) \\
+6^{c}\end{array}$ & NR & $\begin{array}{l}\text { Adachi et al. } \\
2006\end{array}$ \\
\hline $\begin{array}{l}\text { CIC } 320 \text { bid } \\
\text { FP } 330 \text { bid } \\
{[24 \mathrm{w}]}\end{array}$ & $528^{\mathrm{a}, \mathrm{e}}$ & $\geq 80$ & $\begin{array}{l}+11 \\
+38\end{array}$ & NR & NR & $\begin{array}{l}+36^{\mathrm{c}} \\
+22^{\mathrm{c}}\end{array}$ & $\begin{array}{l}\text { Similar to } \\
\text { morning PEF } \\
\text { (data shown } \\
\text { graphically) }\end{array}$ & $\begin{array}{l}\text { Bateman et } \\
\text { al. } 2006 c\end{array}$ \\
\hline $\begin{array}{l}\text { ClC } 320 \mathrm{qd} \\
\text { BUD } 320 \mathrm{qd} \\
{[12 \mathrm{w}]}\end{array}$ & $\begin{array}{l}179 \\
180\end{array}$ & $65-95$ & $\begin{array}{l}-170 \\
-220\end{array}$ & $\begin{array}{l}-6 \\
-8\end{array}$ & $\begin{array}{l}-120(P=0.01 \text { vs BUD }) \\
-210\end{array}$ & $\begin{array}{l}-3^{c} \\
-10^{c}\end{array}$ & $\begin{array}{l}-2^{c} \\
-4^{c}\end{array}$ & $\begin{array}{l}\text { Boulet et al. } \\
2006 a\end{array}$ \\
\hline $\begin{array}{l}\text { CIC } 320 \text { qd } \\
\text { FP } 200 \text { bid } \\
{[12 \mathrm{w}]}\end{array}$ & $472^{\mathrm{a}, \mathrm{e}}$ & $60-80$ & $\begin{array}{l}+171 \\
+186\end{array}$ & NR & NR & NR & NR & $\begin{array}{l}\text { Boulet et al. } \\
2006 \mathrm{~b}\end{array}$ \\
\hline $\begin{array}{l}\text { CIC } 80 \text { qd } \\
\text { CIC } 320 \text { qd } \\
\text { BUD } 200 \text { bid } \\
{[12 \mathrm{w}]}\end{array}$ & $\begin{array}{l}182 \\
195 \\
177\end{array}$ & $\begin{array}{l}73^{\mathrm{c}} \\
72^{\mathrm{c}} \\
72^{\mathrm{c}}\end{array}$ & $\begin{array}{l}+267^{c} \\
+256^{c} \\
+355^{c}\end{array}$ & $\begin{array}{l}+10.8 \\
+10.4 \\
+14.4\end{array}$ & NR & $\begin{array}{l}+12^{\mathrm{c}} \\
+17^{\mathrm{c}} \\
+21^{\mathrm{c}}\end{array}$ & NR & $\begin{array}{l}\text { Hansel et al. } \\
2006\end{array}$ \\
\hline $\begin{array}{l}\text { CIC } 640 \mathrm{bid} \\
\text { PRED } 40 \mathrm{mg} \text { qd } \\
{[2 \mathrm{w}]}\end{array}$ & $130^{\mathrm{a}}$ & NR & $\begin{array}{l}+429 \\
+428\end{array}$ & NR & NR & $\begin{array}{l}+52^{\mathrm{c}} \\
+53^{\mathrm{C}}\end{array}$ & NR & $\begin{array}{l}\text { Postma et al. } \\
2006\end{array}$ \\
\hline $\begin{array}{l}\text { aNumbers of patients } \\
\text { bFP dose } 37 \% \text { higher } \\
\text { 'Reported as a mean } \\
\text { 'Least squares mean } \\
\text { eOpen-label design. } \\
\text { +, increase; -, decreas } \\
\text { NR, not reported; P, Pn }\end{array}$ & $\begin{array}{l}\text { each gro } \\
\text { o maintair } \\
\text { alue. } \\
\text { s budesor } \\
\text { e; A, AM; b }\end{array}$ & $\begin{array}{l}\text { t specified. } \\
\text { ing. } \\
\text { tent-to-treat } \\
\text { ce daily; BUD }\end{array}$ & ysis. & 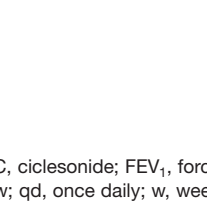 & 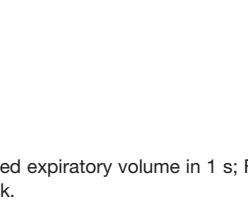 & d vital canacity. FP & 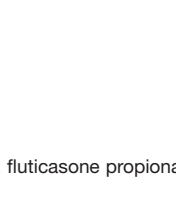 & \\
\hline
\end{tabular}


evening administration of ciclesonide $320 \mathrm{mcg}$ and budesonide $400 \mathrm{mcg}$, onset of treatment effect as evidenced by daily recordings of morning PEF was observed on day 3 with ciclesonide compared with week 2 with budesonide (Biberger et al. 2003). Differences between ciclesonide and active control were not statistically significant. Similarly, maintenance of pulmonary function with ciclesonide $160 \mathrm{mcg}$ (dosed either in the morning or evening) was not statistically different with budesonide $200 \mathrm{mcg}$ twice daily (Niphadkar et al. 2005). However, an 8-week study reported in abstract form reported a significant difference $(P=0.001)$ in PEF in favour of ciclesonide 320 mcg twice daily compared with budesonide $400 \mathrm{mcg}$ twice daily (Adachi et al. 2006).

These results are predominantly obtained from studies of 12 weeks' duration. In a 40-week open-label extension of a 12-week double-blind study evaluating ciclesonide $800 \mathrm{mcg} /$ day and $1600 \mathrm{mcg} /$ day, the improvement in $\mathrm{FEV}_{1}$ was sustained throughout the study period (O'Connor et al. 2002). Over a 52-week study period, $\mathrm{FEV}_{1}$ increased significantly over baseline in patients treated with ciclesonide $200 \mathrm{mcg} /$ day $(P=0.0072)$ and $800 \mathrm{mcg} /$ day $(P=0.0237)$ (Chapman et al. 2002).

Finally, ciclesonide $640 \mathrm{mcg}$ twice daily was as effective as oral prednisolone $40 \mathrm{mg}$ once daily in improving lung function in 130 patients with acute asthma exacerbation, without causing HPA suppression (Postma et al. 2006).

\section{Use of oral corticosteroids}

Since the regular use of oral corticosteroids is associated with significant adverse systemic effects, the impact of inhaled corticosteroid therapy on daily oral corticosteroids required to control symptoms in patients with persistent asthma is an important measure of efficacy. Use of inhaled corticosteroids has been associated with a reduction in the use of oral corticosteroids (Larj \& Bleecker 2004). In a 12-week trial of 141 patients with severe, persistent asthma, use of ciclesonide significantly reduced the need for oral corticosteroid at doses of 320 or $640 \mathrm{mcg}$ twice daily compared with placebo. Mean percentage change in oral corticosteroid use from baseline was -47.39 (low-dose ciclesonide, $P=0.0003$ vs placebo), -62.54 (high-dose ciclesonide, $P=0.0001$ vs placebo), and +4.2 (placebo) (Bateman et al. 2006b).

\section{Asthma symptom score and use of rescue medications}

Evidence from large controlled trials that have evaluated ciclesonide and either placebo or a comparator drug indicate that ciclesonide is at least as effective in reducing patient-reported asthma symptoms and use of rescue medications (Table 7). For example, daily albuterol use as rescue medication was reduced significantly in all ciclesonide-treated groups (80, 160, and $320 \mathrm{mcg}$ ) but increased in the placebo group (Pearlman et al. 2005). A dose-response effect has been demonstrated, with half as many patients receiving ciclesonide $320 \mathrm{mcg}$ twice daily experiencing an asthma exacerbation compared with those taking ciclesonide $160 \mathrm{mcg} / \mathrm{day}$ (23 [6.7\%] vs 43 [12.7\%] patients) (Bateman et al. 2006a). The higher dose was also associated with significantly lower use of rescue medication $(P=0.0005)$ and improved symptom scores $(P=0.0108)$ than the lower dose.

In one study comparing inhaled doses of ciclesonide 80 mcg once daily, ciclesonide $160 \mathrm{mcg}$ once daily, and fluticasone propionate $88 \mathrm{mcg}$ twice daily in patients with mild-to-moderate persistent asthma, the percentage of days without asthma symptoms and without the need for rescue medications (84-87\% for mild disease; $70-79 \%$ for moderate disease) was similar for all treatment groups and was highest during the last 4 weeks of the 12-week study (Magnussen et al. 2005). This increase in the last 4 weeks of a 12week trial was also observed by Buhl et al. (2005b). The percentage of symptom-free days was higher in those patients treated with ciclesonide $(91 \%)$ than in patients treated with fluticasone $(83 \%$, significance not reported), although the percentage of days not requiring rescue medication was comparable (89 vs $91 \%$, respectively) (Buhl et al. 2005b). A full publication of this study by the same authors reported comparable changes in asthma symptom scores for ciclesonide and fluticasone (reductions of 0.75 and 0.86, respectively) (Buhl et al. 2005a). Ciclesonide $320 \mathrm{mcg}$ once daily was comparable to fluticasone 200 mcg twice daily in percentage of days without symptoms ( $88 \%$ both groups) or use of rescue medication ( 85 and $84 \%$, respectively) after 12 weeks in 472 patients with moderate asthma (Boulet et al. 2006b). Bateman et al. (2006c) adds to the evidence that ciclesonide is equivalent in efficacy to fluticasone.

Patients treated with ciclesonide $160 \mathrm{mcg}$ (dosed either in the morning or in the evening) or budesonide $200 \mathrm{mcg}$ twice daily experienced equivalent periods of symptom-free days $(89,91$, and $93 \%$, respectively) (Niphadkar et al. 2005). In addition, other outcomes including rescue medication use, days with control of asthma symptoms, and days without PEF fluctuation were maintained versus baseline with no significant differences between the three groups. In contrast, Adachi et al. (2006) reported significantly lower use of rescue medication $(P=0.007)$ and improved symptom scores $(P=0.008)$ with ciclesonide $320 \mathrm{mcg}$ twice daily compared with budesonide 400 mcg twice daily after 8 weeks' treatment in 319 patients with moderate to severe asthma. Similarly, although overall judged as having comparable efficacy, ciclesonide $320 \mathrm{mcg}$ once daily resulted in significantly more symptom-free days compared with budesonide $320 \mathrm{mcg}$ once daily in 359 patients with persistent asthma (Boulet et al. 2006a).

\section{Use in children}

The efficacy of ciclesonide in children has been compared with placebo, budesonide, and fluticasone.

In a large double-blind, randomized trial involving 1031 children aged 4-11 years, mean $\mathrm{FEV}_{1}$ percent predicted increased by $11.97,13.58$, and 14.17, and mean absolute $\mathrm{FEV}_{1}$ increased by 250,280 , and $290 \mathrm{~mL}$ versus placebo after 12 weeks' treatment with ciclesonide 40,80, and $160 \mathrm{mcg}$ once daily, respectively (Gelfand et al. 2006). Morning and evening PEF also increased, the latter by $12.27,18.34$, and $15.78 \mathrm{~L} / \mathrm{min}$. The changes seen with ciclesonide 80 and $160 \mathrm{mcg} /$ day were significant versus 
Table 7 | Effect on symptoms and use of rescue medications of ciclesonide compared with placebo and active treatment in patients with asthma (level 2 evidence; all trials in adults, randomized)

$\begin{array}{lll}\begin{array}{l}\text { Treatment }(\mathrm{mcg}) \\ \text { [duration] }\end{array} & \mathrm{n} & \begin{array}{l}\text { Baseline FEV }_{1} \\ (\% \text { of predicted }\end{array}\end{array}$

Outcome

Reference

\section{[duration]}

( $\%$ of predicted)

Symptom-free days (\%)

Use of rescue medication (puffs/day)

\section{Placebo-controlled trials}

$\mathrm{CIC} 80$ qd

CIC 320 qd

Placebo

[12 w]

$\mathrm{CIC} 80$ qd

$\mathrm{CIC} 160$ qd

257

$\mathrm{CIC} 320$ qd

250

Placebo

[12 w]

CIC 320 bid

CIC 640 bid

Placebo

[12 w]

\section{Comparator trials}

CIC 320 qd 399

BUD 400 qd

[12 w]

CIC 160 qd

FP 88 bid

[12 w]

CIC 160 qd A

CIC 160 qd $P$

BUD 200 bid

[12 w]

$\mathrm{CIC} 320$ qd

319

$\mathrm{CIC} 320$ bid

BUD 400 bid

[8 w]

CIC 320 bid

FP 330 bid

[24 w]

CIC 320 qd $\quad 179$

BUD 320 qd $\quad 180$

[12 w]

CIC 320 qd

FP 200 bid

[12 w]

CIC 80 qd $\quad 182$

CIC 320 qd

BUD 200 bid

[12 w]

CIC 640 bid

PRED $40 \mathrm{mg}$ qd

[2 w]

130
60-90

$60-85$

NR

Median number of symptom-free days was higher in patients treated with CIC vs placebo

$0^{\mathrm{a}}$

$0^{\mathrm{a}}$

$+0.5^{\mathrm{a}}$

NR

$80-100$

79

77

89

91

93

NR

Similar between groups

$43.6^{d}$

25.8

88

88

Approx. $40 \%$ for all treatment groups

73

72

$177 \quad 72$

NR

Similar between groups
$-0.86^{\mathrm{a}}(P \leq 0.001)$

$-1.02^{\mathrm{a}}(P \leq 0.001)$

$-1.04^{\mathrm{a}}(P \leq 0.001)$

$+0.42^{a}$

$-0.07^{a}$

$-0.08^{a}$

$+0.32^{\mathrm{a}}$

Similar between groups

Biberger et al. 2003

NR

$-0.44^{\mathrm{c}}$

NR

$-1.00^{\mathrm{a}}$

$-1.21^{\mathrm{a}}$

Similar between groups

Pearlman

et al. 2005

Bateman et

al. $2006 \mathrm{~b}$

Buhl et al.

2004,

2005a,b

Niphadkar et al. 2005

Adachi et al. 2006

Similar between groups

Bateman et al. $2006 \mathrm{c}$

Boulet et al. 2006a

$57.5^{\mathrm{b}}$

$53.6^{\mathrm{b}}$

Boulet et al. 2006b

$89^{b}$

Hansel et al. 2006

-1.00 $(P<0.001)$

$-1.04^{\mathrm{a}}(P<0.001)$

Similar between groups
Postma et al. 2006

achange from baseline.

bPercentage of days without use.

${ }^{c} P=0.029$ vs $\mathrm{CIC} 320 \mathrm{qd}, P=0.007$ vs BUD.

$\mathrm{d} P=0.017$.

+, increase; -, decrease; bid, twice daily; A, AM; BUD, budesonide; CIC, ciclesonide; FEV 1 , forced expiratory volume in $1 \mathrm{~s}$; FP, fluticasone propionate; NR, not reported; P, PM; qd, once daily. 
Table 8 | Effect on quality of life of ciclesonide compared with placebo or active treatment (level 2 evidence; all studies randomized, multicenter, double-blind, parallel-group, placebo-controlled, 12 weeks' duration)

\begin{tabular}{|c|c|c|c|c|}
\hline Treatment (mcg) & $\mathbf{n}$ & Baseline $\mathrm{FEV}_{1}$ ( $\%$ of predicted) & Outcome: patients achieving an MID $(\geq 0.5)$ in QOL score $(\%)$ & Reference \\
\hline \multicolumn{5}{|c|}{ Studies in adults and adolescents aged $>12$ years } \\
\hline CIC 160 bid & 531 & $40-65$ & 42.5 & \multirow[t]{4}{*}{ Bernstein et al. 2005} \\
\hline CIC 320 bid & & & 43 & \\
\hline FP 440 bid $^{a}$ & & & 58.8 & \\
\hline Placebo & & & 26.8 & \\
\hline $\mathrm{CIC} 80 \mathrm{qd}$ & 1015 & $60-85$ & 47 & \multirow[t]{4}{*}{ Nayak et al. 2005} \\
\hline $\mathrm{CIC} 160 \mathrm{qd}$ & & & 50 & \\
\hline CIC 320 qd & & & 50.6 & \\
\hline Placebo & & & 31 & \\
\hline \multicolumn{5}{|c|}{ Study in pediatric patients aged $7-17$ years } \\
\hline $\mathrm{CIC} 40 \mathrm{qd}$ & 793 & $60-85$ & 46.1 & \multirow{4}{*}{$\begin{array}{l}\text { Miller et al. 2005; } \\
\text { Gelfand et al. } 2006\end{array}$} \\
\hline $\mathrm{CIC} 80 \mathrm{qd}$ & & & 50 & \\
\hline CIC 160 qd & & & 52.5 & \\
\hline Placebo & & & 36.5 & \\
\hline $\mathrm{CIC} 160 \mathrm{qd}$ & 340 & NR & 53.8 & \multirow[t]{2}{*}{ Vermeulen et al. 2006} \\
\hline BUD 400 qd & 173 & & 50.6 & \\
\hline
\end{tabular}

placebo. These improvements were associated with significantly more symptom-free days among children receiving ciclesonide 80 (52.44\%; $P<0.0001)$ and $160 \mathrm{mcg} /$ day $(48.77 \% ; P=0.0139)$ compared with placebo (42.52\%), and significantly lower use of rescue medication $(P<0.01)$. Ciclesonide improved symptom scores and reduced nighttime awakening at all three doses.

There is evidence that ciclesonide $160 \mathrm{mcg} /$ day, given either as a single dose or as $80 \mathrm{mcg}$ twice daily, is as effective as fluticasone $88 \mathrm{mcg}$ twice daily and budesonide $400 \mathrm{mcg}$ once daily. In 556 children, ciclesonide and fluticasone increased mean $\mathrm{FEV}_{1}$ by 298 and $297 \mathrm{~mL}$, respectively, after 12 weeks (Pedersen et al. 2004a). Corresponding increases in mean morning and evening PEF were 31 and $29 \mathrm{~L} / \mathrm{min}$ with ciclesonide, and 34 and $29 \mathrm{~L} / \mathrm{min}$ with fluticasone.

Mean $\mathrm{FEV}_{1}$ increased by $220 \mathrm{~mL}$ in 340 children aged $6-11$ years following 12 weeks' treatment with ciclesonide and by $253 \mathrm{~mL}$ in 173 receiving budesonide (von Berg et al. 2006). Asthma symptoms were absent in an almost identical proportion of days in each group (74\% for ciclesonide and $73 \%$ for budesonide), and both drugs were comparable in improving symptom scores and reducing rescue medication use.

\section{Quality of life}

HRQOL measures offer an important patient perspective into the therapeutic management of asthma. Because asthma is a chronic disease that may affect a patient's ability to participate in normal daily activities including work, school, and extracurricular activities, it is important to include the impact of a medication on quality of life in a determination of its effectiveness and place in therapy. There is often a disconnection between medicationinduced changes in airways as assessed by the clinician and patient perceptions of their functional status. The effect of treatment on HRQOL is now recognized as an important gauge of therapy and should be used as a determinant of treatment effect. HRQOL measurement provides the clinician with important insight into the burden of disease and provides an appreciation of the effect of treatment on functional status. Treatments with positive HRQOL effects may improve patient compliance with therapy and improve overall patient satisfaction (Gerth van Wijk 2005).

Although several HRQOL tools have been used to evaluate HRQOL in patients with asthma, in the ciclesonide studies that provided HRQOL information, the Asthma Quality of Life Questionnaire (AQLQ) and the Pediatric Asthma Quality of Life Questionnaire (PAQLQ) were the tools used for assessment. The reliability and validity of the AQLQ has been verified in several studies (Gupchup et al. 1997; van der Molen et al. 1997; Sanjuas et al. 2002). The AQLQ is a 32-item, four-domain (symptoms, emotional function, activity limitation, and breathlessness) questionnaire that can be interviewer- or self-administered. Using this questionnaire, a change in score of 0.5 is considered the minimum change necessary for clinical significance.

A separate pediatric-based questionnaire is necessary for children because it is clear that conventional measures of the effectiveness of therapy (asthma severity, spirometry, and medication use) and parents' perceptions of a child's functionality weakly correlate with how children actually feel and their ability to participate in activities of daily life (Juniper et al. 1996). 
The PAQLQ is a 23-item questionnaire that is appropriate for children between the ages of 7 and 17 years and focuses on three domains (symptoms, emotional function, and activity limitation). A change in score of 0.5 reflects a minimally important difference. Both interviewer- and self-administration formats of the PAQLQ are available (Juniper 1997).

The impact of ciclesonide on the HRQOL of patients with asthma has been assessed (Table 8) (Bernstein et al. 2005; Miller et al. 2005; Nayak et al. 2005). In one study that included patients with severe persistent asthma ( $\left.\mathrm{FEV}_{1} 40-65 \%\right)$, clinically significant changes in AQLQ $(\geq 0.5)$ were noted in all three groups receiving ciclesonide 160 or $320 \mathrm{mcg}$, or fluticasone $440 \mathrm{mcg}$ twice daily (Bernstein et al. 2005). The change in AQLQ with fluticasone was greater than that noted with either dose of ciclesonide, although the statistical significance of this difference was not reported. These HRQOL studies were only conducted for a period of 12 weeks, therefore, it is not known if improvements in QOL are sustainable or whether the changes translate to significant longterm patient improvement.

\section{Tolerability}

A major component of the rationale for the development of ciclesonide is the minimization of local and systemic side effects often experienced with inhaled corticosteroids. Ciclesonide has been well tolerated in clinical trials with most adverse effects reported as mild. It is anticipated that the airway activation of ciclesonide will reduce the incidence of adverse effects compared with currently available inhaled corticosteroids. Although there are some data from longer term studies, the bulk of the evidence supporting the lack of systemic effects with ciclesonide therapy is limited to 12 weeks of treatment. Further long-term data will be necessary to confirm if ciclesonide offers an advantage over the other inhaled corticosteroids.

\section{Local adverse effects}

Local adverse effects associated with the use of inhaled corticosteroids include perioral dermatitis, tongue hypertrophy, cough during inhalation, and sensation of thirst. The most frequently reported clinically significant effects are oropharyngeal candidiasis and dysphonia (Roland et al. 2004). Deposition of active medication in the oropharyngeal cavity is dependent on the delivery device and can be decreased with the use of spacers. These adverse effects, while they are not considered to be clinically serious, are troublesome and may affect patient adherence (Goeman 2002).

Oropharyngeal deposition of ciclesonide (metered-dose inhaler with hydrofluoroalkane propellant) is reduced compared with fluticasone (metered-dose inhaler with hydrofluoroalkane propellant) and budesonide (metered-dose inhaler with CFC) (Nave et al. 2005a; Richter et al. 2005). This reduction in oral deposition is expected to correlate with a lower rate of local adverse effects. In a pooled analysis of phase II and phase III studies, data from 12251 patients who received ciclesonide $(n=7706)$, active control [budesonide, beclomethasone, or fluticasone $(n=3330)]$, or placebo $(n=1215)$
Table 9 | Incidence of oropharyngeal adverse events with ciclesonide compared with placebo or active treatment $^{\mathrm{a}}$ (adapted from Engelstätter et al. 2005)

\begin{tabular}{|llcl|}
\hline \multirow{2}{*}{ Adverse event } & \multicolumn{3}{c|}{ Incidence of event/patient year } \\
\cline { 2 - 4 } & Ciclesonide & Placebo & Active control ${ }^{\text {b }}$ \\
\hline Candidiasis & 0.02 & 0.02 & 0.07 \\
Hoarseness & 0.03 & 0.03 & 0.07 \\
\hline $\begin{array}{l}\text { a'Cough not reported. } \\
\text { beclomethasone, budesonide, or fluticasone. }\end{array}$ \\
\hline
\end{tabular}

for 12 weeks were analyzed to determine the incidence of oropharyngeal adverse events (candidiasis, hoarseness, cough) (Engelstätter et al. 2005). The incidence of local adverse events per patient year was similar in the ciclesonide and placebo group; oral candidiasis and hoarseness occurred less frequently in the ciclesonide group compared with the active control group ( $P$ value not reported) (Table 9). In a subanalysis, fewer patients in the ciclesonide group experienced an oral adverse event compared with patients in the fluticasone subgroup $(P<0.0001)$.

There is limited evidence that this lower frequency of oral adverse effects is maintained when treatment exceeds 12 weeks. A single open-label study that followed a 12-week placebo-controlled trial reported oropharyngeal side effects in 10 of 228 patients treated with ciclesonide (3.5\%) (Chapman et al. 2002). After 24 weeks of treatment in an open-label study involving 528 patients, oral candidiasis or dysphonia were reported by $5.1 \%$ of patients receiving ciclesonide $320 \mathrm{mcg}$ twice daily, significantly less than the $12.8 \%$ for fluticasone $330 \mathrm{mcg}$ twice daily $(P=0.0014)$ (Bateman et al. 2006c).

\section{Systemic adverse effects}

Systemic effects of inhaled corticosteroids occur because a large percentage (80\%) of an administered dose of active drug is swallowed (Roland et al. 2004). Additional systemic exposure can occur as the drug is absorbed from the pulmonary fluid into the systemic circulation (Hübner et al. 2005). The amount of drug that is available to the systemic circulation, method of delivery, and lipophilicity of the drug influence risk of systemic side effects. The extent of systemic exposure with inhaled corticosteroids is typically reported by the magnitude of HPA axis suppression, serum and urinary cortisol concentrations, and effects on bone growth or mineralization. Systemically active corticosteroids bind to glucocorticoid receptors in the hypothalamus and adrenal pituitary causing a decrease in the amount of corticotropinreleasing hormone and adrenocorticotropic hormone leading to decreased cortisol secretion (Lipworth et al. 2005).

\section{HPA axis suppression and cortisol levels}

There is clear evidence that ciclesonide does not cause HPA axis suppression after 12 weeks of treatment. 
In a 12-week, double-blind, randomized, placebo-controlled study assessing the systemic adverse effect potential of ciclesonide, 164 patients were randomized to receive fluticasone propionate (CFC propellant) $440 \mathrm{mcg}$ daily, ciclesonide $320 \mathrm{mcg}$ once daily, ciclesonide $320 \mathrm{mcg}$ twice daily, or placebo (Lipworth et al. 2005). Serum and urine cortisol levels were measured at baseline, week 6 , and week 12. HPA axis function was preserved with ciclesonide in doses of up to $640 \mathrm{mcg} /$ day. After 12 weeks, changes in mean peak serum cortisol levels and 24-hour urinary free cortisol levels following both doses of ciclesonide were not significantly different from placebo, in contrast to fluticasone propionate $880 \mathrm{mcg} / \mathrm{day}$, which was associated with significant reductions of $9-10 \%$ in peak serum cortisol levels and $60 \%$ in 24-hour urinary free cortisol levels (Lipworth et al. 2005). Other studies have also reported a lack of effect of ciclesonide therapy on serum and 24-hour urinary free cortisol corrected for creatinine (Postma et al. 2001; Pearlman et al. 2005).

In a 12-week study of once-daily inhaled ciclesonide $80 \mathrm{mcg}$ $(n=182)$ or $320 \mathrm{mcg}(n=195)$ compared with inhaled budesonide 200 mcg $(n=177)$ twice daily, no relevant changes in 24-hour urinary cortisol excretion were observed in patients receiving ciclesonide. However, patients who received budesonide had a statistically significant suppression of urine cortisol $(P<0.05)$ (Hansel et al. 2006).

Sixty adult patients were randomized in a single-center, doubleblind, double-dummy, parallel-group study evaluating HPA axis suppression associated with the use of ciclesonide compared to fluticasone in patients with moderate-to-severe asthma (Szefler et al. 2005). Patients received either ciclesonide $320 \mathrm{mcg}$ twice daily, ciclesonide 640 mcg twice daily, fluticasone 440 mcg twice daily, fluticasone $880 \mathrm{mcg}$ twice daily, or placebo for 29 days. Mean serum cortisol $\mathrm{AUC}_{0-24 \mathrm{~h}}$ at the end of treatment was significantly suppressed in the high-dose fluticasone group. A cosyntropin stimulation test showed no statistically significant differences among the groups. Twenty-four-hour urinary cortisol levels were significantly increased from baseline at week 4 compared with placebo in the ciclesonide $320 \mathrm{mcg}$ twice-daily group ( $P=0.0224$; 95\% confidence intervals $0.0023,0.0283)$; the other treatment groups did not demonstrate any change in urinary cortisol levels (Szefler et al. 2005).

In addition, two abstracts report preliminary information on HPA axis suppression with ciclesonide and an active control in adults (Ukena et al. 2003) and in children (Pederson et al. 2004b). In the study comparing ciclesonide $320 \mathrm{mcg} /$ day with budesonide $400 \mathrm{mcg} / \mathrm{day}$ in adults, no relevant change in laboratory parameters or urine cortisol were noted after 12 weeks of treatment (Ukena et al. 2003). In the pediatric phase III comparator study, the difference between urinary free cortisol levels in patients treated with ciclesonide $80 \mathrm{mcg}$ twice daily $(+1.54 \mathrm{nmol} / \mathrm{mmol}$ creatinine) versus patients treated with fluticasone propionate $88 \mathrm{mcg}$ twice daily $(-1.83 \mathrm{nmol} / \mathrm{mmol}$ creatinine) was statistically significant $(P=0.0062)$ (Pedersen et al. 2004b).

The lack of suppressive effect appears to be independent of dose. A study of high-dose ciclesonide $800 \mathrm{mcg} /$ day substantiates the lack of suppressive effect with ciclesonide. The HPA axis function of 12 healthy volunteers was preserved after $800 \mathrm{mcg} /$ day of inhaled doses of ciclesonide (400 mcg twice daily, $800 \mathrm{mcg}$ in the morning, or $800 \mathrm{mcg}$ in the evening) given for 7 days. The effect was independent of time of administration (Weinbrenner et al. 2002). There is further evidence for the lack of effect on HPA axis from 26 patients with asthma receiving ciclesonide $320 \mathrm{mcg}$ once daily, or $640 \mathrm{mcg}$ once or twice daily, or fluticasone $440 \mathrm{mcg}$ or $880 \mathrm{mcg}$ twice daily in randomized, double-blind fashion for 9 days (Derom et al. 2005). Although the study was short duration and involved few patients, 24-hour cortisol secretion was unaffected by ciclesonide, even at the high dose.

Furthermore, there is evidence that HPA axis suppression does not appear to develop with longer-term ciclesonide treatment (Chapman et al. 2002; O'Connor et al. 2002). In these placebocontrolled ciclesonide trials, patients received an individualized dose of ciclesonide for 40 weeks following the initial 12-week study. Serum cortisol levels were increased compared with the former steroid treatment (budesonide $800-2000 \mathrm{mcg} / \mathrm{day}$ or equivalent) (O'Connor et al. 2002). There was no evidence that ciclesonide suppressed the HPA axis as evidenced by changes in serum and urine cortisol measurements (Chapman et al. 2002). Importantly, these long-term data have been replicated in 661 children aged 5-8.5 years, with ciclesonide 40 or $160 \mathrm{mcg} / \mathrm{day}$ associated with minimal changes in urinary-free cortisol levels after 1 year of treatment (Bernstein et al. 2006).

\section{Bone mineralization and growth}

Orally administered glucocorticoids are known to affect bone mineralization, decrease osteocalcin concentration in healthy volunteers, and decrease bone density in the lumbar spine (Jones et al. 2002; van Staa et al. 2002). In young patients, these factors impact bone growth. In adults, these effects can increase the risk of fracture. Glucocorticoids assert their effect on bone predominantly by decreasing bone formation through a negative effect on the function and lifespan of osteoblasts (Jones et al. 2002). Despite the limited systemic absorption of inhaled corticosteroids, the long-term administration of these agents is also believed to impact bone metabolism (Roland 2004; O'Connell 2005). Laboratory indices of bone formation (bone-specific alkaline phosphatase and serum osteocalcin) have been followed to quantify the impact of therapy.

Over a 52-week study in patients with moderate-to-severe asthma, increased levels of serum bone-specific alkaline phosphatase and serum osteocalcin were observed in patients after receiving ciclesonide compared with the levels obtained while they were on their prestudy doses of steroid $(P<0.05)$, suggesting that the impact of ciclesonide treatment on bone metabolism in these patients was significantly less than the effects of previously used inhaled corticosteroid therapies (O'Connor et al. 2002).

Studies measuring the effect of lower leg growth in children have been reported. Twenty-four children aged 6-12 years were randomized to receive a daily dose of ciclesonide $40 \mathrm{mcg}$, $80 \mathrm{mcg}, 160 \mathrm{mcg}$, or placebo over a 12-week period. No statistically significant differences in knemometry results, height 
measurements, or HPA suppression occurred in any of the patients (Agertoft \& Pedersen 2005). Growth velocity was unaffected by 1 year of treatment with ciclesonide in 661 children aged 5-8.5 years (Skoner et al. 2006). During treatment, mean linear growth velocity was $5.73 \mathrm{~cm} /$ year with ciclesonide $40 \mathrm{mcg} /$ day, $5.6 \mathrm{~cm} /$ year with ciclesonide $160 \mathrm{mcg} / \mathrm{day}$, and $5.75 \mathrm{~cm} /$ year with placebo. In the same patient cohort, ciclesonide also had no effect on skeletal maturity, as measured by chronologic to bone age ratio (Neffen et al. 2006). A shift from normal to high ratio was seen in 17 patients, although a treatment-related effect seems unlikely since fewer of those taking higher-dose ciclesonide were affected (1.1\%), and the incidence with low-dose ciclesonide was similar to that with placebo (4.3 and 4\%).

\section{Drug interaction potential}

The pharmacokinetic properties of ciclesonide are such that significant drug-drug interactions are not expected with its use. Ciclesonide is activated in airways at the desired site of action and very little of the drug is available to the systemic circulation. A single pharmacokinetic study evaluating ciclesonide and erythromycin coadministration demonstrated a lack of interaction between these medications (Nave et al. 2005b). As with other inhaled corticosteroids, drug-drug interactions are not considered to be a clinical concern.

\section{Resource utilization}

At present, economic evidence comparing the use of ciclesonide with other inhaled corticosteroids is not available. Ciclesonide, from a clinical standpoint, appears comparable to budesonide and fluticasone propionate, but with less propensity for systemic adverse effects. It is possible that the once-daily administration of ciclesonide coupled with its low adverse event profile will give ciclesonide an advantage over other inhaled corticosteroids. Use of ciclesonide over one of the other inhaled corticosteroids will ultimately depend on additional long-term data as they become available, including its long-term adverse effect profile and impact on HRQOL. Economic data, including the effect of ciclesonide treatment on both direct and indirect medical costs, will need to be factored into the decision-making process to determine its place in therapy with regard to the other inhaled corticosteroids.

In general, inhaled corticosteroids are considered the most effective therapy for reducing asthma exacerbations and studies have reported that the use of these agents reduce medical costs and decrease the use of healthcare resources (Halpern 2003). A recent meta analysis examined the long-term effects of inhaled corticosteroids, long-acting beta ${ }_{2}$ agonists, leukotriene pathway modifiers/receptor antagonists, and antiimmunoglobulin $\mathrm{E}$ antibody therapies. Of these agents, inhaled corticosteroids were found to have the greatest impact on the reduction of asthma exacerbations (55\% vs placebo; relative risk 0.46 , $95 \%$ confidence intervals $0.34,0.62 ; P<0.001$ ) (Sin et al. 2004). These reductions in exacerbations translate to economic savings from decreased hospitalizations, decreased emergency room visits, and a decrease in physician visits and use of rescue medications. In order for an inhaled corticosteroid to produce its positive effects, it must be used continuously to keep the inflammatory process in check.

\section{Patient group/population}

Asthma affects all age groups, from pediatric patients to the elderly. Available evidence for ciclesonide demonstrates efficacy in patients with persistent asthma that is similar to other currently available inhaled corticosteroids. Inhaled corticosteroids are the mainstay of treatment for patients with persistent asthma. Any patient with symptom frequency that suggests persistent disease would benefit from maintenance treatment with an agent such as ciclesonide. The evidence for a lack of effect on growth rate and skeletal maturation in children in the long term (1 year) indicates that ciclesonide is suitable for pediatric use.

\section{Dosage, administration, and formulations}

Ciclesonide $\left(\right.$ Alvesco ${ }^{\circledR}$ ) is available in a $80 \mathrm{mcg}$ and $160 \mathrm{mcg}$ metered-dose inhaler, with hydrofluoroalkane propellant. Approved dosages and indications vary between different countries, and readers are advised to consult their local prescribing information (Anon. 2006). The recommended starting dose is usually $160 \mathrm{mcg}$ once daily, preferably in the evening. Maintenance on $80 \mathrm{mcg}$ once daily may be effective in some patients. No dosage adjustment is necessary in the elderly or in patients with hepatic or renal impairment.

\section{Place in therapy}

The unique pharmacokinetic profile of ciclesonide confers a potential advantage in that there is minimal systemic absorption of active drug, which appears to be sustained as shown by a lack of HPA axis suppression after 1 year of treatment. Further evidence will confirm if efficacy is sustained in the longer term with approved doses, and if the decrease in systemic exposure is linked to an overall increased safety profile. The decrease in adverse effects that have been observed in short-term trials may be beneficial in some patients for whom the local effects are bothersome and may lead to disruptions in therapy. In addition, patients with more severe disease who are being treated with higher doses of inhaled corticosteroids may also benefit because of the apparent decrease in systemic exposure associated with ciclesonide use. The drug appears to have a role in the management of pediatric patients with asthma, and is not associated with growth retardation in long-term use.

The available evidence indicates that ciclesonide is as effective as fluticasone and budesonide for the management of persistent asthma, as shown by improvements in lung function parameters, symptom scores, and use of rescue medications. Inhaled corticosteroids are considered to be the foundation of asthma management in patients with persistent disease (Table 2). It is expected that ciclesonide will be included in updated guidelines as a primary therapy along with other inhaled corticosteroids. Currently, the use of combination inhalers 
(beta-agonist/corticosteroid) is recommended as a means to streamline therapy in patients with persistent asthma. (Anon. 2005b; British Thoracic Society 2005). Ciclesonide is not available in a combination formulation and therefore patients would be required to have two separate inhalers. There is evidence that lung function improvements are maintained for up to 1 year of treatment.

The impact of ciclesonide use on overall disease course, DALYs, and hospitalization rate as compared with other currently available inhaled corticosteroids has not been reported. These measures are important to the overall evaluation of the expected role of ciclesonide in the management of persistent asthma.

\section{References}

Adachi M, Miyamoto T, Masuda K, Sakai T. Equal or superior efficacy of ciclesonide $320 \mathrm{mcg}$ or $640 \mathrm{mcg}$ as compared with CFC-beclomethasone dipropionate $800 \mathrm{mcg}$ in the treatment of patients with moderate to severe asthma. Poster presented at: American Thoracic Society Annual Meeting; May 21, 2006; San Diego, CA. Poster G25.

Anon. Asmanex Twisthaler (package insert). Kenilsworth, NJ Schering Corporation; February 2005a.

Anon. Global strategy for asthma management and prevention. Available at: http://www.ginasthma.com/guidelineitem.asp?|1=2\&l2=1\&intld=60 (accessed July 28, 2005b).

Anon. Alvesco Prescribing Information. Available at: http://www.alvesco.com (accessed June 16, 2006).

Agertoft L, Pedersen S. Short-term lower-leg growth rate and urine cortisol excretion in children treated with ciclesonide. J Allergy Clin Immunol. 2005;115:940-945

Bateman ED, Balint B, Bodzenta-Lukaszyk A, et al. Treatment of severe asthma using ciclesonide $160 \mathrm{mcg}$ once daily or $320 \mathrm{mcg}$ twice daily - a comparison. Poster presented at: American Thoracic Society Annual Meeting; May 23, 2006a; San Diego, CA. Poster K42.

Bateman E, Karpel J, Casale T, Wenzel S, Banerji D. Ciclesonide reduces the need for oral steroid use in adult patients with severe, persistent asthma. Chest. 2006b;129:1176-1187.

Bateman ED, Langan J, Vereecken G, Smau L, Engelstätter R. Efficacy and tolerability of ciclesonide compared with fluticasone propionate in patients with moderate-to-severe asthma. Poster presented at: American Thoracic Society Annual Meeting; May 21, 2006c; San Diego, CA. Poster G23.

Berger WE. Ciclesonide: a novel inhaled corticosteroid for the treatment of persistent asthma-a pharmacologic and clinical profile. Therapy. 2005;2:167-178.

Bernstein D, Nathan R, Ledford D, et al. Ciclesonide, a new inhaled corticosteroid, significantly improves asthma-related quality of life in patients with severe, persistent asthma. J Allergy Clin Immunol. 2005;115:S210.

Bernstein D, Caballero-Fonseca F, Zhang P, Lloyd M, Banerji D. Once-daily ciclesonide has no effect on hypothalamic-pituitary-adrenal-axis function in prepubertal children with mild, persistent asthma. J Allergy Clin Immunol. 2006;117(Suppl. 2):S184 (Abstract 715).

Biberger C, von Behren V, Malek R, et al. Efficacy and safety of ciclesonide compared with budesonide in asthma patients: A randomized 12-week study. Abstract presented at: American Thoracic Society Annual Meeting; May 18, 2003; Seattle, WA. Abstract page A771.

Boulet L-P, Drollman A, Magyar P, et al. Comparative efficacy of once-daily ciclesonide and budesonide in the treatment of persistent asthma. Respir Med. 2006a;100:785-794.

Boulet L-P, Hofbauer P, Voves R, Wolf S, Tiesler C, Engelstätter R. Efficacy and tolerability of ciclesonide (MDI) and fluticasone propionate (Diskus ${ }^{\circledR}$ ) in patients with moderate asthma. Poster presented at: American Thoracic Society Annual Meeting; May 21, 2006b; San Diego, CA. Poster G24.
Bousquet J, Bousquet PJ, Godard P, Daures J-P. The public health implications of asthma. Bull World Health Organ. 2005;83:548-554.

British Thoracic Society, Scottish Intercollegiate Guidelines Network. British guideline on the management of asthma. Available at: http://www.enterpriseportal2.co.uk/filestore/bts/asthmaupdatenov05.pdf (accessed November 14, 2005).

Buhl R, Vinkler I, Magyar P, et al. Once daily ciclesonide and twice daily fluticasone propionate are equally effective in the treatment of patients with asthma. Eur Respir J. 2004;24(Suppl. 48):346s (Abstract 2177).

Buhl R, Vinkler I, Magyar P, et al. Comparable efficacy of ciclesonide once daily versus fluticasone propionate twice daily in asthma. Pulm Pharmacol Ther. 2005a; November 23; [Epub ahead of print].

Buhl R, Wolf S, Tiesler C, et al. Once-daily ciclesonide is as effective as twicedaily fluticasone propionate in improving lung function in patients with mild-tomoderate persistent asthma. Poster presented at: American Thoracic Society Annual Meeting; May 23, 2005b; San Diego, CA. Poster G19.

Chapman KR, Patel P, Boulet LP, et al. Efficacy and long-term safety of ciclesonide in asthmatic patients as demonstrated in a 52 week long study. Eur Respir J. 2002;20(Suppl. 38):373s (Abstract 2328).

Chapman KR, Patel P, D'Urzo AD, et al. Maintenance of asthma control by once-daily inhaled ciclesonide in adults with persistent asthma. Allergy. 2005;60:330-337.

Crim C, Pierre L, Daley-Yates P. A review of the pharmacology and pharmacokinetics of inhaled fluticasone propionate and mometasone furoate. Clin Ther 2001;23:1339-1354.

Derom E, Van De Velde V, Marissens S, Engelstätter R, Vincken W, Pauwels R. Effects of inhaled ciclesonide and fluticasone propionate on cortisol secretion and airway responsiveness to adenosine 5 'monophosphate in asthmatic patients. Pulm Pharmacol Ther. 2005;18:328-336.

Dolovich MB, Ahrens RC, Hess DR, et al; American College of Chest Physicians; American College of Asthma, Allergy, and Immunology. Device selection and outcomes of aerosol therapy: evidence-based guidelines. Chest. 2005;127:335-371.

Drollmann A, Nave R, Steinijans VW, Baumgartner E, Bethke TD. Equivalent pharmacokinetics of the active metabolite of ciclesonide with and without use of the AeroChamber Plus ${ }^{\mathrm{TM}}$ spacer for inhalation. Clin Pharmacokinet. 2006; 45:729-736.

Dyer M, Halpin DMG, Stein K. Inhaled ciclesonide versus inhaled budesonide or inhaled beclomethasone or inhaled fluticasone for chronic asthma in adults: a systematic review. BMC Fam Pract. 2006;7:34.

Engelstätter R, Escher A, Häfner D. Low incidence of oropharyngeal adverse events in asthma patients treated with ciclesonide. Eur Respir J. 2005;1738:255s.

Gauvreau GM, Boulet LR, Postma DS, et al. Effect of low-dose ciclesonide on allergen-induced responses in subjects with mild allergic asthma. J Allergy Clin Immunol. 2005;116:285-291.

Gelfand EW, Georgitis JW, Noonan M, Ruff M. Once-daily ciclesonide in children: efficacy and safety in asthma. $J$ Pediatr. 2006;148:377-383.

Gerth van Wijk R. Assessment of quality of life: advantages and pitfalls. Clin Exp Allergy Rev. 2005;5:32-35.

Goeman DP, Aroni RA, Stewart K, et al. Patients' views of the burden of asthma: a qualitative study. Med J Aust. 2002;177:295-299.

Gupchup GV, Wolfgang AP, Thomas Jl. Reliability and validity of the asthma quality of life questionnaire - marks in a sample of adult asthmatic patients in the United States. Clin Ther. 1997;19:1116-1204.

Halpern MT, Khan ZM, Stanford RH, Spayde KM, Golubiewski M. Asthma: resource use and costs for inhaled corticosteroid vs leukotriene modifier treatment - a meta-analysis. J Fam Pract. 2003;52:382-389.

Hansel TT, Benezet O, Kafé H, et al. A multinational, 12-week, randomized study comparing the efficacy and tolerability of ciclesonide and budesonide in patients with asthma. Clin Ther. 2006;28:906-920.

Hübner M, Hochhaus G, Derendorf H. Comparative pharmacology, bioavailability, pharmacokinetics, and pharmacodynamics of inhaled glucocorticosteroids. Immunol Allergy Clin North Am. 2005;25:469-488. 
Jones A, Fay J, Stone M, Hood K, Roberts G. Inhaled corticosteroid effects on bone metabolism in asthma and mild chronic obstructive pulmonary disease. Cochrane Database Syst Rev. 2002;(1):CD003537.

Juniper EF. How important is quality of life in pediatric asthma? Pediatr Pulmonol Suppl. 1997;15:17-21.

Juniper EF, Guyatt G, Feeny D, Ferrie PJ, Griffith LE, Townsend M. Measuring quality of life in children with asthma. Qual Life Res. 1996;5:35-46.

Kanniess F, Richter K, Bohme S, Jorres RA, Magnussen H. Effect of inhaled ciclesonide on airway responsiveness to inhaled AMP, the composition of induced sputum and exhaled nitric oxide in patients with mild asthma. Pulm Pharmacol Ther. 2001;14:141-147.

Kelly HW. Pharmaceutical characteristics that influence clinical efficacy of inhaled corticosteroids. Ann Allergy Asthma Immunol. 2003;91:326-334.

Langdon C, Adler M, Mehra S, Alexander M, Drollman A. Once-daily ciclesonide 80 or $320 \mathrm{mcg}$ for 12 weeks is safe and effective in patients with persistent asthma. Respir Med. 2005;99:1275-1285.

Larj MJ, Bleecker ER. Therapeutic responses in asthma and COPD. Chest. 2004;126:138S-149S.

Lee DK, Haggart K, Currie GP, Bates CE, Lipworth BJ. Effects of hydrofluoroalkane formulations of ciclesonide 400 microg once daily vs fluticasone 250 microg twice daily on methacholine hyper-responsiveness in mild-to-moderate persistent asthma. Br J Clin Pharmacol. 2004;58:26-33.

Lipworth BJ, Kaliner MA, LaForce CF, et al. Effect of ciclesonide and fluticasone on hypothalamic-pituitary-adrenal axis function in adults with mild-to-moderate persistent asthma. Ann Allergy Asthma Immunol. 2005;94:465-472.

Magnussen H, Hellwig M, Hellbardt S, Josten J, Engelstätter R. Ciclesonide $80 \mathrm{mcg}$ or $160 \mathrm{mcg}$ once-daily and fluticasone propionate $88 \mathrm{mcg}$ twice-daily similarly reduce asthma symptoms and rescue medication use in patients with mild-to-moderate asthma. Poster presented at: American Thoracic Society Annual Meeting; May 23, 2005; San Diego, CA. Poster G20.

Masoli M, Fabian D, Holt S, Beasley R. Global burden of asthma. Available at: http://www.ginasthma.com/reportltem.asp?!1=2\&l2=2\&intld=94 (accessed July 28, 2005).

Miller D, Ratner P, Condemi J, et al. Once-daily ciclesonide improves quality of life in pediatric patients with asthma. J Allergy Clin Immunol. 2005;115:S211.

Nave R, Bethke TD, van Marle SP, Zech K. Pharmacokinetics of

[14C]ciclesonide after oral and intravenous administration to healthy subjects. Clin Pharmacokinet. 2004;43:479-486.

Nave R, Zech K, Bethke TD. Lower oropharyngeal deposition of inhaled ciclesonide via hydrofluoroalkane metered-dose inhaler compared with budesonide via chlorofluorocarbon metered-dose inhaler in healthy subjects. Eur J Clin Pharmacol. 2005a;61:203-208.

Nave R, Drollmann A, Steinijans VW, Zech K, Bethke TD. Lack of pharmacokinetic drug-drug interaction between ciclesonide and erythromycin. Int J Clin Pharmacol Ther. 2005b;43:264-270.

Nave R, Gunawardena KA, Zech K, Bethke TD. Pharmacokinetic disposition of inhaled ciclesonide and its metabolite desisobutyryl-ciclesonide in healthy subjects and patients with asthma are similar. Int J Clin Pharmacol Ther. 2006;44:1-7.

Nayak A, Charous B, Finn A, et al. A novel inhaled corticosteroid ciclesonide significantly improves quality of life in patients with mild-to-moderate asthma. J Allergy Clin Immunol. 2005;115:S210.

Neffen H, Ruff M, Zhang P, Lloyd M, Banerji D. Ciclesonide, administered once daily, has no effect on skeletal maturity in prepubertal children with mild, persistent asthma. J Allergy Clin Immunol. 2006;117(Suppl. 2):S184 (Abstract 714).

Newman S, Salmon A, Nave R, Drollmann A. High lung deposition of ${ }^{99 m}$ Tc-labeled ciclesonide administered via HFA-MDI to patients with asthma. Respir Med. 2006;100:375-384.

Niphadkar P, Jagannath K, Joshi JM, et al. Comparison of the efficacy of ciclesonide 160 microg qd and budesonide 200 microg bid in adults with persistent asthma: a phase III, randomized, double-dummy, open-label study. Clin Ther. 2005;27:1752-1763.

O'Connell EJ. Optimizing inhaled corticosteroid therapy in children with chronic asthma. Pediatr Pulmonol. 2005;39:74-83.
O'Connor BJ, Kilfeather S, Cheung D, et al. Treatment of moderate to severe asthma with ciclesonide: a long-term investigation over 52 weeks. Eur Respir J. 2002;20(Suppl. 38):406s (Abstract 2579).

Pearlman DS, Berger WE, Kerwin E, LaForce C, Kundu S, Banerji D. Once-daily ciclesonide improves lung function and is well tolerated by patients with mildto-moderate persistent asthma. J Allergy Clin Immunol. 2005;116:1206-1212.

Pedersen S, Garcia ML, Manjra Al, Vermeulen JH, Venter L, Engelstätter R. Ciclesonide and fluticasone propionate show comparable efficacy in children and adolescents with asthma. Eur Respir J. 2004a;24(Suppl. 48):346s(Abstract 2176).

Pedersen S, Gyurkovits K, von Delft KHE, Boss H, Engelstätter R. Safety profile of ciclesonide as compared with fluticasone propionate in the treatment of children and adolescents with asthma. Eur Respir J. 2004b;24(Suppl. 48):346s. (Abstract 2175).

Postma DS, Sevette C, Martinat Y, Schlosser N, Aumann J, Kafe H. Treatment of asthma by the inhaled corticosteroid ciclesonide given either in the morning or evening. Eur Respir J. 2001;17:1083-1088.

Postma DS, Ind PW, Magnussen H, van den Berge M. A double-blind, randomized, controlled study comparing the efficacy and safety of inhaled ciclesonide with oral prednisolone in patients with an asthma exacerbation. Poster presented at: American Thoracic Society Annual Meeting; May 21, 2006; San Diego, CA. Poster G27.

Reynolds NA, Scott LJ. Ciclesonide. Drugs. 2004;64:511-519; discussion 520-521. Richter K, Kanniess F, Biberger C, Nave R, Magnussen H. Comparison of the oropharyngeal deposition of inhaled ciclesonide and fluticasone propionate in patients with asthma. J Clin Pharmacol. 2005;45:146-152.

Rohatagi S, Luo Y, Shen L, et al. Protein binding and its potential for eliciting minimal systemic side effects with a novel inhaled corticosteroid, ciclesonide. Am J Ther. 2005;12:201-209.

Roland NJ, Bhalla R, Earis J. The local side effects of inhaled corticosteroids: current understanding and review of the literature. Chest. 2004;126:213-219.

Sanjuas C, Alonso J, Prieto L, et al. Health-related quality of life in asthma: a comparison between the St George's respiratory questionnaire and the asthma quality of life questionnaire. Qual Life Res. 2002;11:729-738.

Sin DD, Man J, Sharpe H, Gan WQ, Man SF. Pharmacological management to reduce exacerbations in adults with asthma: a systematic review and metaanalysis. JAMA. 2004;292:367-376.

Skoner D, Maspero J, Kundu S, Loyd M, Banerji D. Ciclesonide, administered once daily, has no effect on growth velocity in prepubertal children with mild, persistent asthma. J Allergy Clin Immunol. 2006;117(Suppl. 2):S11 (Abstract 44).

Subbarao P, Duong M, Adelroth E, et al. Effect of ciclesonide dose and duration of therapy on exercise-induced bronchoconstriction in patients with asthma. J Allergy Clin Immunol. 2006;117:1008-1013.

Szefler S, Rohatagi S, Williams J, Lloyd M, Kundu S, Banerji D. Ciclesonide, a novel inhaled steroid does not affect hypothalamic-pituitary-adrenal axis function in patients with moderate-to-severe persistent asthma. Chest. 2005;128:1104-1114.

Taylor DA, Jensen MW, Kanabar V, et al. A dose-dependent effect of the novel inhaled corticosteroid ciclesonide on airway responsiveness to adenosine-5'monophosphate in asthmatic patients. Am J Respir Crit Care Med. 1999;160:237-243.

Ukena D, Biberger C, von Behren V, et al. Ciclesonide significantly improves pulmonary function when compared with budesonide: a randomized 12-week study. Eur Respir J. 2003;22(Suppl. 45):411s (Abstract 2640).

van der Molen R, Postma D, Schreurs A, et al. Discriminative aspects of two generic and two asthma-specific instruments: relation with symptoms, bronchodilator use and lung function in patients with mild asthma.

Qual Life Res.1997;6:353-361.

van Staa TP, Leufkens HGM, Cooper C. The epidemiology of corticosteroidinduced osteoporosis: a meta analysis. Osteoporos Int. 2002;13:777-787.

Vermeulen JH, Latos T, Müller T, Engelstätter R. Quality of life is improved by ciclesonide $160 \mathrm{mcg}$ once daily and budesonide $400 \mathrm{mcg}$ once daily in pediatric patients with persistent asthma. J Allergy Clin Immunol. 2006;117(Suppl. 2):S184 (Abstract 716). 
von Berg A, Garcia ML, Hellbardt S, Bethke TD. Ciclesonide $160 \mathrm{mcg}$ once daily is as effective as budesonide $400 \mathrm{mcg}$ once daily in pediatric patients with persistent asthma. J Allergy Clin Immunol. 2006;117(Suppl. 2):S11 (Abstract 42). Weinbrenner A, Huneke D, Zschiesche M, et al. Circadian rhythm of serum cortisol after repeated inhalation of the new topical steroid ciclesonide. $J$ Clin Endocrinol Metab. 2002;87:2160-2163.

Weinstein S, Friedman B, Kundu S, Banjeri D. Ciclesonide is effective and welltolerated in adults/adolescents with severe, persistent asthma. Poster presented at the American Thoracic Society Annual Meeting; May 23, 2005; San Diego, CA. Poster G26.
Wickersham R, Novak K. Drug facts and comparisons. St Louis, MO: Wolters Kluwer Health; 2005.

Wilson AM, Duong M, Pratt B, Dolovich M, O’Byrne PM. Anti-inflammatory effects of once daily low dose inhaled ciclesonide in mild to moderate asthmatic patients. Allergy. 2006;61:537-542.

Correspondence: Paul Chrisp, Core Medical Publishing, Mere House, Brook Street, Knutsford, Cheshire WA16 8GP, UK or at editor@coreevidence.com 